\title{
ESTÉTICA DE LA SED: LONQUÉN 10 AÑOS, DIEZ AÑOS DESPUÉS
}

\author{
POR \\ Pablo Oyarzún R. \\ Universidad de Chile \\ P. Universidad Católica de Chile
}

HeCHOS

En los hornos de una mina de cal abandonada, en el sector de Lonquén, al suroeste de Santiago, fueron encontrados a fines de 1978 quince restos humanos. Eran los cadáveres de quince campesinos de la zona, detenidos por carabineros en octubre de 1973, a poco menos de un mes del golpe militar. Los familiares habían presentado un recurso de amparo en 1974, cuando ya mediaba tiempo desde su desaparición. Supuestamente, los campesinos habían sido conducidos al campo de prisioneros del Estadio Nacional, y el oficial de turno había registrado falazmente su ingreso también supuesto. Pero hacia fines de 1978 un sacerdote de la Iglesia Católica recibió una denuncia anónima que señalaba la existencia de los mencionados restos. La noticia se filtró al poco tiempo por el único medio de prensa que mantenía un grado de desobediencia vigilada respecto de la autoridad militar. Sobre esa base se inició una investigación a cargo de un ministro en visita que se restó a la complicidad que vinculaba al poder judicial con la dictadura. Sin embargo, tiempo después tuvo que declararse incompetente, al establecerse que los detenidos habían sido ultimados a bala por personal uniformado. El caso pasó a la Fiscalía Militar, que llegó a decretar encargatoria de reo en contra de los agentes implicados. Sin embargo, en virtud del Decreto Ley de Amnistía de 1978, la sentencia judicial los sobreseyó total y definitivamente. Se dispuso que los cadáveres — sólo uno de ellos era reconociblefuesen entregados a los familiares, lo que no llegó a ocurrir: mientras éstos estaban reunidos en un templo para celebrar la misa fúnebre, sin mediar consulta ni aviso, funcionarios del Servicio Médico Legal enterraron los restos en una fosa común del Cementerio Municipal de Isla de Maipo. Brutalmente repetían así el acto del entierro clandestino.

Estos mismos hechos fueron registrados y expuestos ampliamente por el importante jurista nacional, Máximo Pacheco, perteneciente a la Comisión de Derechos Humanos, en el libro Lonquén. El libro tiene la estructura de un dossier, en el cual se recogen ordenadamente todos los documentos del proceso judicial, desde la denuncia y la investigación hasta las resoluciones y apelaciones, que cubren un año a contar de diciembre de 1978. Una introducción narra las primicias del proceso: la denuncia y el hallazgo, con sus sombríos detalles. Pacheco, precisamente, integraba el grupo que dio 
con los cadáveres en los hornos, y luego tuvo a su cargo la conducción de la parte acusadora en el juicio. Editado por primera vez en marzo de 1980, la circulación del libro fue prohibida, y sólo seis años después pudo tenerse público acceso a él.

En el archivo de las atrocidades del régimen militar Lonquén ocupa un lugar eminente. Y no sólo por la saña con que actuaron los agentes policiales, por la impunidad escandalosa que les fue asegurada, por el ocultamiento y la mentira oficial voceada a cuatro vientos, rasgos diseminados a través de todos los actos represivos de la dictadura en los diecisiete años de su duración. Es que, por una parte, durante los primeros tiempos del gobierno de Pinochet, en Chile sólo corrían rumores de la extrema violencia represiva —asesinatos masivos, lanzamiento de cuerpos a cauces, zanjones y mar, persecuciones, torturas, secuestros y desapariciones-, y desde luego ningún medio de comunicación estaba dispuesto a hacerse cargo de esa circulación de verdades soterradas. El hallazgo de Lonquén fue la primera prueba indesmentible, el inicio de la emergencia del mal acontecido y por acontecer, la cual dura hasta nuestros días. Y por otra parte, había y sigue habiendo en ese hecho un espesor simbólico que comparte con hitos semejantes como el caso de los degollados y el caso de los quemados. ${ }^{1}$ Frente a la instalación de Gonzalo Díaz es preciso tener en cuenta este espesor.

OCASIÓN, EMPLAZAMIENTO, MATERIALES

El 12 de enero de 1989 se inaugura en la galería santiaguina Ojo de Buey, en una restringida sala rectangular, la instalación Lonquén 10 Años. Los visitantes constatan un conjunto reducido de elementos. Por tres costados de la sala, sobre sus paredes, penden 14 cuadros idénticos con marcos neoclásicos negros, lacados, bajo cada uno de los cuales se ha fijado un ordinal romano de bronce, numerando la secuencia. Una primera peculiaridad salta a la vista en estos módulos, tan familiares y domésticos por su hechura, fisonomía y tamaño: en la base, al lado izquierdo del marco, empotrada en él, sobresale una pequeña repisa, igualmente negra y lacada, que soporta un vaso con agua a medio llenar. Encima de cada cuadro se cierne un aplique de bronce que con su luz aurática prestigio burgués de la pintura - dirige la atención hacia el vidrio protector, hacia la inscripción que ha sido practicada en la cara interior del vidrio y hacia el campo de lija oscura que ocupa el fondo. Peculiar es también la ordenación de estos cuadros: en tanto doce se extienden a lo largo de uno de los muros, los dos restantes, numerados con el VI y el XIV, están respectivamente colgados, solitarios, de otros dos muros de la sala. En el cuarto muro, se impone a la mirada un armazón casi piramidal de cuartones de pino

\footnotetext{
${ }^{1}$ Ambos casos ocurrieron cuando promediaban los años ochenta. El primero es el de tres profesores de un colegio capitalino secuestrados mediante un estudiado operativo de inteligencia, cuyos cadáveres aparecieron días después. El segundo, el de dos estudiantes, una muchacha y un joven, que fueron apresados por una patrulla militar en días de protesta social, rociados con bencina, quemados horriblemente y abandonados después semicarbonizados en las afueras de Santiago. Cuando fueron hallados, el joven agonizaba y falleció a las pocas horas; la muchacha, después de una prolongada estadía en el extranjero, y tras haber sido sometida a múltiples intervenciones quirúrgicas, vive y trabaja ahora en Santiago.
} 
rudimentario tras el cual hay un amontonamiento rectangular de unas doscientas veinte piedras redondeadas, bolones de río, amarradas por un alambrado de fierro: una estructura de contención, que previene el derrumbe de la pila. Cada una de las piedras lleva impreso en blanco su correspondiente número. En el costado derecho superior del armazón un tubo de argón, a manera de acento o de trazo, despide su luz lívida.

No bien asomarse al lugar ya se tiene la impresión de estar ingresando a un antro. Una vez en el interior, y por la calculada disposición de los elementos, el espacio acusa una signatura escénica. A causa de una especie de recogimiento que lo circunstante induce en el espectador, evoca un templo. Ni necesidad tienen los visitantes de que se les explique el motivo que subyace a la muestra. El nombre "Lonquén” está, para todos ellos, expresamente unido al historial de los crímenes de la dictadura. Tiene aquel espesor que mencionaba antes, aquel valor ejemplar, que — también lo estaba diciendo — lo asimila a otros hechos terribles que jalonan ese historial, que constituyen el inventario sistemático de las operaciones de un poder omnímodamente represivo: el golpe, el degüello, la quema, la desaparición. ${ }^{2}$

\section{LECTURAS}

Sin embargo, la total obviedad de la referencia, que se proclamaba ya desde el título, no rimaba con la áspera dificultad del desciframiento de lo allí expuesto. En una entrevista de la época, Díaz advertía sobre la multiplicidad de lecturas a que se abría el conjunto. Bien podría haber extremado la advertencia, sugiriendo que para encaminarse por ese laberinto de sentidos era preciso aprender a leer de nuevo. A desasirse, primeramente, del credo que supone que el sentido se esconde detrás de los signos o los objetos, o que está más allá, en algún lugar ideal, y sólo se refleja en ellos su resplandor furtivo. Por eso, la metáfora del espesor, de la densidad simbólica, sólo es buena para llamar la atención sobre la dificultad, no para designar su índole propia. Más —o también menos— que un espesor constituido por estratos de sentido cuya geología pudiera ser unívocamente descriptible, y que se ordenaran jerárquicamente a partir de su último fundamento, era ésa una densidad de experiencia, minada en todas partes por la falta de guías ciertas, obligada a cada instante a decidir por su cuenta y riesgo su sentido, tan frágil y transitorio como discutible.

En el breve texto que Gonzalo Díaz destinó a la presentación del autor, ${ }^{3}$ había una clara alusión a esa densidad de experiencia, en la explicación del largo tiempo que tuvo que tomarse el artista para abordar ese hecho obsesivo, abierto como un abismo:

Sólo después de diez años de retención metabólica, de mirar lo que ocultan esas fauces fotográficas de medio punto - arquitectura adecuada a la magnitud de una masacre— se me ha hecho posible enfrentar directamente el Via Crucis de este pavoroso asunto.

\footnotetext{
${ }^{2}$ Las tres primeras ya fueron identificadas por Platón (Gorgias, 476ss., a propósito del castigo); la cuarta es invención moderna, demasiado moderna: el secuestro y la desaparición (como política de Estado) presuponen el sujeto, y si recaen, desde luego, sobre el cuerpo, es a aquél a quien afectan esencialmente.

${ }^{3}$ En la contraportada del catálogo de la muestra, que alojaba en su interior el ensayo "Sueños privados, ritos públicos”, de Justo Pastor Mellado.
} 
Lonquén, el punctum pestilente que aflora con porfía desde la ciénaga espesa del monótono discurso oficial, revelando su exacta contradicción. Un ejemplo —que desgraciadamente ha multiplicado sus manifestaciones que resume en cada piedra de escándalo de sus oscuros arcos, todos los lugares y fosas comunes del régimen. El paradigma que soporta y condiciona todos sus éxitos...

Esa retención de que habla Díaz no se debe sin más a una voluntad, a una disciplina y a un control consciente, sino que ha sido forzada por la evidencia enceguecedora de la ruina, de esa especie de monumento funerario de "piedra sobre piedra", reliquia de un estadio rudimentario de la industria; ha sido forzada, en fin, por la evidencia del negro boquerón de la entrada. Una retención que es un ejercicio admirable de supervivencia en el arte; de supervivencia del arte, se diría asimismo, "en medio de la hecatombe”. Ese ejercicio, que cuenta entre los que han sido y son esenciales en la escena artística chilena, hizo posible llevar la relación con la historia política y social del país a un estatuto distinto al del testimonio, la ilustración, la denuncia, la extrapolación metafórica, en una palabra: a un estatuto que ya no pertenece, de ningún modo, al régimen de la representación. Otros intentaron también este esquive, tornando más complejos los vínculos. Pero la paciencia peculiar de Díaz pudo gestar una poética de extrema pulcritud y perspicacia; Lonquén 10 Años es su primicia deslumbrante. Sostuve que para leer esta obra era preciso aprender a leer de nuevo; es que en ella el arte lee lo real de distinto modo: ya no representa. Así, aquel ejercicio impide la conversión simbólica de lo vivido — de lo vivido a ciegas—, para designar el socavón y la cuenca sobre los cuales esa misma existencia agredida se equilibra, a duras penas. Fatalidad arquitectónica, ésta, que tiene en la configuración política de un sistema de vida — el más indeseable — su momento crucial: para construir, para erigir, se tiene indefectiblemente que excavar el suelo en que ha de levantarse lo construido. Fundar es desfondar. "Cavamos el pozo de Babel”, anotaba Kafka en su Diario. Cierto: los fundadores se apresuran a cubrir el abismo — con tanto más apremio y ostentación, cuanto mayor ha sido el capital de violencia que han invertido - con emblemas, ceremonias y efemérides. Díaz se impuso la tarea arqueológica - y ya se advierte cómo esta rama de una hipotética ciencia de los vestigios (en la que también participa, a su modo, el juez que indaga) está señalada en el inventario numérico de las piedras - la tarea arqueológica, pues, de mostrar ese desfondamiento.

LA DISPOSICIÓN

Según propia declaración de Díaz, la matriz del vía crucis fue un hallazgo impremeditado en el apuro por establecer un principio de seriación para los módulos, de suerte que los dieciocho originales se redujeron, según esa pauta, a catorce. El punto tiene su importancia, porque insinúa que el empleo de esa matriz no obedece en Díaz a una intención simbólica o alegórica, sino, ante todo, a la solución de un problema formal. ${ }^{4}$

${ }^{4}$ Me he referido con algún detenimiento a este aspecto en “La cuna del delfín” (1998), a propósito de Quadrivium. Es cierto que la cuestión de esta formalidad puede malentenderse, que puede pensarse, sin más, que se habla de un recurso estetizante. Pero ya se sabe que en arte la apelación a la forma — si todavía tiene sentido emplear estas viejas categorías — compromete el contenido, y 
Ampliamente ha insistido Díaz en este descubrimiento, hasta completar siete instalaciones, como en una especie de ciclo exacto. Empezando por Lonquén, hay que registrar El Jardín del Artista (Montevideo, 1993), Yo soy el Sendero (Winnipeg, 1993), Fábulas Amorales de la Provincia (Castro, 1994), El Padre de la Patria (La Habana, 1994), La Tierra Prometida (San Diego, 1997) y Quadrivium ad usum delphini (Santiago, 1999).

Ya se precisó que en la primera ocasión la secuencia estricta de las catorce estaciones fue alterada por la colocación separada del sexto y del decimocuarto elemento (de otra manera ocurre en la oportunidad presente, y ya habrá ocasión de comentarlo.) En todo caso, aquella alteración distó de ser inocua. En la sexta estación, la Verónica enjuga el rostro de Jesús, cuya efigie queda milagrosamente estampada en el paño; en la última, el cadáver del redentor es depositado por sus fieles en la tumba de José de Arimatea. La doble dislocación puede ser interpretada de muchos modos, y se podría creer que la clave religiosa del vía crucis podría prestar amparo a las primeras perplejidades del espectador, fijando la dirección para emprender el trabajo hermenéutico. Pero así como la plétora de sentidos que se articula en esta obra no se debe a una determinación básica de los elementos por el patrón devocional y teológico que aportaría el vía crucis, tampoco ha de creerse que aquí se trata de asimilar el tormento y la destrucción de las víctimas de Lonquén a la pasión de Cristo. Díaz prescinde de cristianizar el hecho, manteniéndolo en la dureza irremisible de su facticidad. Ciertamente, también aquí se trata de la historia de una pasión. Pero el apartamiento de la estación de la imagen y de la estación del entierro — y se tendrá en mientes, a propósito de esto, el vínculo nunca esclarecido que ata la imagen a la muertemarcan una diferencia fundamental: las víctimas, en este caso (bien lo decía el autor de una reseña de la muestra [Oses 50]), carecen de rostro y de sepultura. Si la historia de Jesús permanece imantada hacia la presencia — hacia la parusía—, la de estos míseros campesinos se hunde en el abismo de la ausencia, de la desaparición.

LA INSCRIPCIÓN

El 12 de junio de 1900 Freud envía una carta a su amigo Wilhelm Fliess en que le pregunta si en la casa de Bellevue "podrá leerse algún día una placa de mármol que diga así”

En esta casa,

el 24 de julio de 1895 ,

le fue revelado al doctor Sigmund Freud

el secreto de los sueños

La fecha remite a un jueves legendario, en que Freud llevó a cabo por primera vez el análisis completo de un sueño, refrendando la tesis de que el sentido esencial de la elaboración onírica es la realización del deseo. Ese análisis fundacional figura en el segundo capítulo del opus magnum de Freud y se conoce con el nombre del sueño de "la inyección de Irma”.

que aquélla jamás puede ser limpiamente desgajada de éste. En el uso que hace del esquema del vía crucis, Díaz bien sabe la carga que lleva; ese saber es también una distancia. 
Parodiando esta expresión clásica del deseo del descifrador del deseo, Díaz estampa en la cara interior de cada vidrio la frase:

En esta casa,

el 12 de enero de 1989,

le fue revelado a Gonzalo Díaz

el secreto de los sueños

Hay quien ha querido leer este lema como un desplante, una especie de presunción: gesto descomedido de artista que se arrogaría un privilegio en el saber de aquello que — cosa que haría más grave, gravísimo, ese gesto — por su espantoso desmán arruina todo privilegio, condena toda exclusividad.

Pero se verá: en el libro de Pacheco que posee el artista, al costado de un pasaje de la introducción en que se refiere que "un sacerdote había recibido la denuncia de un particular sobre ‘la existencia de un cementerio de cadáveres en la localidad de Lonquén’”, puede leerse, escrito a mano y en rojo "le fue revelado el secreto de los sueños". El motivo de la confesión - que es decisivo para esta obra — se constituye en una delgada hebra que vincula al sacerdote y al artista, y ciertamente Lonquén tiene un sello de intimidad, de verdad sólo murmurada, que hace del espacio entero el lugar de una revelación o, dicho de manera más precisa, de la inminencia de una revelación. Pero a diferencia del sacerdote, que en la cabina oscura del confesionario recibe, en un susurro, el relato de lo pavoroso, y está investido para ello, el artista carece de sanciones instituidas para hacerse depositario de una verdad semejante, más aún: como hombre de la imagen es tentado inevitablemente a figurar esa verdad, a representarla y, si lo hace, a traerla a un espacio de familiaridad, al prestigio del espectáculo, atezándola sin remedio. Pero esta verdad no admite lustre. De ello, más que de ninguna otra cosa, tiene que estar enterado el artista: si quiere habérselas con tal verdad, a ello tiene que conformar su comportamiento. No puede postularse como el sujeto - el ministro - de un saber privativo, tampoco puede asumir ninguna función vicaria que lo autorice en parecido conocimiento. No sólo carece de las ínfulas, sino que también le está vedado el dominio de las claves. Únicamente puede ser el depositario lúcido de una ausencia de saber, y quedarle fiel a ésta. De esa laya ha sido la decisión de Díaz. Le es revelado el secreto, sí, pero se le revela como secreto. También para él permanece impenetrable. No queda opaco el conocimiento de los hechos, ciertamente, pero sí el saber de lo que ha acontecido en tales hechos, del modo y el alcance en que éstos dislocan la experiencia y su bagaje. El artista, entonces, no se iguala al sacerdote; pero el arte adquiere aquí, raramente, los aires de un rito sacramental, aunque de uno que no dispone en absoluto de las cifras para administrar lo que se le revela. Se parece — el artista, aquí- a quien despierta de un largo sueño perturbador, con el barrunto vago de una verdad que irremediablemente se le escapa. ${ }^{5}$

\footnotetext{
${ }^{5}$ Aunque ese sueño también puede tener otra cara. Un dato que conviene tener a mano es la iniciación pictórica de Díaz como productor autónomo, cuando acudía a cierto simbolismo onírico con carácter de clausura autobiográfica. Era, de algún modo, la ficción de una infancia paradisíaca, de un "espacio feliz", como llamó él mismo a la pintura al explicar su abandono (por ejemplo, en "Unos sueños sin sepultura” [Brodsky 32]). En cierto sentido, la autobiografía sigue siendo una dimensión
} 
HACES DE SIGNIFICACIÓN

¿Cómo dar cuenta del horror en el arte? Si la obra de arte está abocada indefectiblemente a la presencia, y el horror es ese exceso de presencia por el cual ésta se anula, es abolida, ¿cuál será, entonces, la economía de la presentación que puede dar cuenta de él? ¿Cuál es, en esa economía, la imprescindible organización de las referencias, las remisiones, las alusiones en virtud de las cuales ha de anunciarse lo que, como tal, no puede sino ser impresentable? Parecida cuestión radical determina esta obra de Díaz, y puede decirse que venía apuntándose solapadamente desde antes, tal vez a lo largo de una década, desde el tiempo en que la mano todavía se gozaba en el juego untuoso del pincel.

En el texto de Díaz que previamente se mencionó el punto queda marcado con rigor e insistencia:

\footnotetext{
Una condición para poner el dedo del arte en la llaga de la política: una extrema delicadeza que haga de esta usura una construcción soportable, delicadeza que ha demorado diez años en tejerse, distancia y peso suficiente para habilitar una relación inesperada: la actividad del sueño y el ejercicio sacramental de la confesión. Confesamos nuestros crímenes como soñamos nuestros deseos. Algo sale a luz, a nuestro entendimiento y a la luz pública, un conocimiento, un expreso secreto, un dato suficiente, materiales para un signo concreto.

Oscuridades fragmentadas que hilvanamos para iluminar un hecho, un lugar exacto, un episodio, una escena nocturna de puro horror.
}

Delicadeza es la palabra de Díaz. Para "poner el dedo del arte en la llaga de la política” es preciso usar guante. Las pruebas deben permanecer intactas, aunque para ello sea necesario clasificarlas, numerarlas: fijar escrupulosamente su condición de restos y rastros de la constelación de unos hechos. Tal sería el comportamiento que exige la hipotética ciencia de los vestigios a que aludí más atrás. Esta ciencia, sin duda, sólo existe en sus disciplinas tributarias: la indagación judicial o detectivesca, la arqueología, la paleontología; podría creerse que el psicoanálisis se ha postulado como su paradigma. En Lonquén 10 Años asistimos a una subrepticia igualación del arte con ella. La delicadeza es su temple, dice Díaz. También se podría hablar de discreción, que es el sello de esta obra. La discreción (discretio, de cerno, cribar, tamizar, separar ${ }^{6}$ ) es la operación que propiamente corresponde al secreto. Y secreto (secretum, de igual origen) es lo separado, lo apartado del conocimiento público, lo que no puede ser re-presentado (condición y maniobra de la publicidad) sin insanable adulteración. ${ }^{7}$ Pero este secreto, el que viene a ser revelado aquí,

de la obra de Díaz, pero no, ciertamente, como narración de incidentes personales, sino como trabajo impersonal, involuntario, brote espontáneo de la memoria.

${ }^{6}$ La selección de las piedras por su tamaño — que tuvo que encargar el artista para su instalaciónse hace por medio de un sistema de tamices, que retienen en la parte superior las más grandes, luego las medianas, y por fin las pequeñas.

${ }^{7}$ La pintura — si nos atenemos a su determinación tradicional— es continua: labora con lo líquido y lo viscoso, se desliza entre los espacios intercalares para amasar desde allí las cosas hacia el lucimiento de su redonda presencia. 
no es algo en particular, no es un contenido determinado ni nada que pueda ser capitalizado en ningún saber, intención o conducta; es el hecho del secreto, el mero hecho de que hay secreto (ya lo estaba diciendo antes), que se cela, precisamente, en el acaecer de los hechos: singulares, discontinuos, rapsódicos. De ahí, entonces, la delicadeza, la discreción esencial de la obra, que no pretende interpretar (atribuir un sentido) al crimen (la palabra viene también de cerno), que por su exceso desmadra asimismo todo sentido. Sólo dispone haces de significación, que en su juego cruzado, en la sorda connivencia entre sus distintos elementos, en las relaciones de confirmación y mentís que pueden leerse entre ellos, impone por doquier la desazón.

EL SECRETO

En el texto de Díaz que se reproducía atrás se habla de la inesperada relación entre la confesión y el sueño. Esa relación — que tiene la forma de un cruce, de un quiasmatiene su punto en el secreto. "Confesamos nuestros crímenes como soñamos nuestros deseos”, anota Díaz. El apunte remite a la explicación que da Freud de lo siniestro, das Unheimliche. ${ }^{8}$ Se recordará que en el ensayo sobre este afecto el padre del psicoanálisis se apoya inicialmente en una elucidación del término ofrecida por Schelling: "Se denomina unheimlich todo lo que, debiendo permanecer secreto, oculto... no obstante, se ha manifestado”, para avanzar más tarde — análisis de El arenero de Hoffmann mediantea sentar su tesis de que lo siniestro es el retorno de lo familiar reprimido. Descontada la importancia que esta tesis tiene para la aventura del psicoanálisis, con ella incorporó Freud una categoría al orbe de la estética sin la cual, creo, no sería posible pensar buena parte del arte contemporáneo. Esa categoría bien puede definir el clima de la obra Lonquén, de la operación que en ella tiene lugar, a condición de que se conciba de manera suficiente lo que en este caso se llama "secreto".

Pues aquí — esto ya lo estaba insinuando — no ha de entenderse el secreto como lo meramente oculto que es susceptible de ser, sin reservas, expuesto a la luz. El secreto no son los hechos que han permanecido ajenos a la mirada y la conciencia públicas, sino lo que se cela en ellos. De otro modo, la desazón o la tensión se aplacarían con el conocimiento, como ocurre con los acertijos. Pero el verdadero secreto no pertenece al orden del conocimiento. Por eso, también, la descripción o el relato de unos hechos abismales no los allana, no acalla el rumor por el cual se acusa eso que tienen de incurablemente otro. Su cumplida eficacia, cuando la alcanzan, estriba en tornar sensible ese rumor.

Decía que lo aciago, lo inquietante del secreto, es que hay secreto. Se tiene que decir algo más: que ese hay determina a cada cual en lo que es. Pues, ciertamente, el secreto constituye la individualidad: ésta misma es impensable e imposible sin secreto. Guardando algo en secreto lo protejo de la mirada, el deseo y la intromisión ajena, lo aparto de la esfera de conocimiento y de acción de los otros; pero si algo me reclama ser guardado en secreto, es porque yo mismo, en mi singularidad irreductible, estoy con ello en juego, es porque allí despunta mi deseo; al guardar algo en secreto, me guardo (me protejo, me deseo) a mí

${ }^{8}$ En el catálogo de referencia Mellado concluye su comentario con una rápida alusión a este tema. 
mismo, me aparto yo mismo. Para decirlo más claramente: no es un sujeto ya constituido el que tiene la facultad de guardar un secreto, sino que esta misma guarda es, a la vez, su condición de posibilidad y su origen. No hay sujeto sin secreto, así como no hay sujeto que no esté ligado a unos hechos. Pero éstos no son sino esquirlas de la gran explosión, que no cesa de detonar, a la que llamamos historia. En su infinita fragmentación, guardan en cifra la huella de su procedencia de la totalidad estallada. El secreto del secreto, entonces, es la totalidad, que le pena al sujeto en su inapelable separación. Y ciertos hechos tienen la fuerza — por su espanto, su júbilo, su pesantez o su agudeza — para hacerle sentir, sin esquive, esa huella.

Sin descripción ni relato, desde su perfecta impavidez, la obra hace emerger — tarea de memoria tenaz - el hecho del secreto, que está encriptado en todo hecho: y nos impone, ante la evidencia de estos hechos, que nos confesemos lo que somos, lo que hemos llegado a ser.

LA SED

Un vestigio de agua recorre la muestra, como el estero que riega la zona de Lonquén, y que tributa su menudo caudal al río Maipo, el mayor de la región de Santiago. Un vestigio, más que material — pues por doquier impera el contraste-, un vestigio de sentido: en los bolones de río, en la transparencia del vidrio, en el papel lija de esmeril que ocupa el campo de los cuadros (lija de pulir metales que, por el requisito de su empleo, se llama lija al agua), en el sueño y su liquidez, y — por sustracción — en la rigurosa sequedad del conjunto. Es cierto: el elemento mismo está también allí, contenido en los catorce vasos ordinarios que reposan sobre sus respectivas ménsulas, pero está para realzar por hipérbole, si puedo decirlo así, su porfiada falta. ${ }^{9}$

Árido es el conjunto, definitivamente árido. De cal. Cada una de sus piezas está aislada en sí misma, indiferente a los vínculos que pudieran adivinarse entre unas y otras. Así como se relaciona con el agua, así también se relaciona la instalación con el sentido.

La exhibición de Lonquén 10 Años fue clausurada, mes y medio después de su inauguración, con una performance que tenía el aire de un rito funerario, de un acto de reparación. Un poco evocando al grupo que se abrió paso en los hornos a golpes de herramientas y alumbrado por una improvisada antorcha de papel, el artista acudió a la sala provisto de un martillo y una Polaroid, depositados sobre un pequeño carro de arrastre. Blandiendo el martillo, rompió uno a uno los vidrios de los catorce cuadros, profiriendo en cada ocasión el nombre de cada uno de los campesinos asesinados, y fotografiando los pedazos de vidrio diseminados por el suelo, que después eran colocados cuidadosamente sobre la ménsula. Fue todo. Ni un ángel — diría Benjamin— podría volver a juntar lo destrozado. Pero la acción parecía tender un cabo invisible entre la imagen y la sepultación.

\footnotetext{
${ }^{9}$ Varias asociaciones ensayaron los comentaristas de la instalación en su momento a propósito de los recipientes y su contenido, haciendo pie en su doméstica banalidad o en el simbolismo del líquido. El vaso de agua, señalaban unos, alude al recipiente sobre el velador, al cual echa mano el que se despierta de un mal sueño para apaciguar su inquietud.
} 
Prevalece la sed, insaciable. ¿Sed de sentido, acaso? No lo será, si sólo se trata de averiguar qué quiere decir lo expuesto. Nada quiere decir Lonquén 10 Años. Rige en su silencio adusto, al otro lado de las intenciones y pretensiones, como la grieta de los sueños por donde inopinadamente aflora la masa de la memoria. Pero sí lo será, a condición de que eso que llamamos "sentido" sea sólo el gesto en virtud del cual nos abrimos a lo acontecido en su crudeza y su insondable particularidad para dejarnos determinar por ello. Sed de justicia, entonces.

DiEZ AÑOS DESPUÉS

Estructura y elementos de la obra siguen siendo los mismos, a más de una década de distancia de su primera exhibición. Su puesta en escena ha cambiado, sin embargo. En lugar de la ocupación original de los cuatro muros, aquí los módulos están enfilados simétricamente a lo largo de dos paredes laterales, ${ }^{10} \mathrm{y}$ la armazón con las piedras y el trazo de argón se yergue al fondo, contra la tercera pared. La arquitectura teatral del templo se ingresa en una nave- ha recibido ahora más acentuación. La media pirámide trunca preside todo el ámbito ocupando — diríase — el sitio del altar. Su característica de túmulo en que se invierten aquellas "fauces fotográficas” que obsesionaron al artista se ha hecho, tal vez, más notoria. Enfrente, el vano estrecho por donde ingresa el visitante al ámbito, vuelve a signarlo como antro, como cripta. ${ }^{11}$ Nada ocurre allí: es el acaecer llevado al grado cero, al silencio deletéreo. En la clausura opresiva de la escena muda, en su quietud ominosa, nada más se percibe que el zumbido bajo del tubo de argón. Y, sin embargo, se presiente allí un ruidillo que sólo podría verse, la rascadura de la lija en la cara interior del vidrio. El rumor no se acalla.

\section{Bibliografía}

Brodsky, Roberto. Hoy 602 (Santiago, 1989): 32.

Oses, Darío. “Un espacio enlutado”. Apsi 288 (Santiago, 1989): 50.

Oyarzún R., Pablo. "La cuna del delfín”. 1998.

Pacheco G., Máximo. Lonquén. 2ª ed. Santiago: Aconcagua, 1983.

Pastor Mellado, Justo. Sueños privados, ritos públicos: en ocasión de la muestra Lonquén

10 años, de Gonzalo Díaz: que se realiza en Galería Ojo de Buey. Santiago: La

Cortina de Humo, 1989.

\footnotetext{
${ }^{10}$ El formato simétrico recuerda tres instalaciones anteriores basadas en el vía crucis: Yo soy el Sendero (Winnipeg, 1993), Fábulas Amorales de la Provincia (Castro, 1994), El Padre de la Patria (La Habana, 1994) y La Tierra Prometida (San Diego, 1997).

${ }^{11}$ Esta portezuela de $40 \mathrm{~cm}$. de ancho repite la que daba entrada a Quadrivium ad usum delphini (Santiago, 1998).
} 